\title{
BIOTECHNOLOGIES
}

\section{Influence of Implants Surface Properties on Bone Tissue Formation in the Ectopic Osteogenesis Test}

\author{
S. V. Nadezhdin, E. V. Zubareva, Yu. E. Burda, Yu. R. Kolobov, \\ M. B. Ivanov, G. V. Khramov, and A. Yu. Afanas'ev
}

Translated from Byulleten'Eksperimental'noi Biologii i Meditsiny, Vol. 162, No. 12, pp. 786-789, December, 2016 Original article submitted May 4, 2016

\begin{abstract}
We studied the influence of the characteristics of oxide porous coatings on osteogenesis and integration of new bone tissue and titanium implant surface in the ectopic osteogenesis test. Implants with coating with pore size 2-20 $\mu$ exhibit better osteogenic and osteoconductive characteristics than implants with homogenous surface and smooth relief (pore size 0.5$5.0 \mu$ ). Physical characteristics of the surface of the material along with chemical composition of the coating are essential for the formation of bone tissue and its integration with the implant.
\end{abstract}

Key Words: osteogenesis; implantation; in vitro experiments

The significance of chemical composition and physical characteristics of implants for activation of mesenchymal stem cells in the osteogenic direction remains the object of discussions for scientists engaged in creation of new materials for traumatology and dentistry $[4,5,8,9]$. However, the results indicating the influence of the surface topography on the integration processes and bone tissue remodeling are contradictory and require thorough studies.

Here we analyzed the influence of the characteristics of porous oxide coating on osteogenesis and integration of the new bone tissue with the surface of a titanium implant.

\section{MATERIALS AND METHODS}

The study was carried out on inbred male Wistar rats $(n=24 ; 240-250 \mathrm{~g})$. Experiments were carried out with due consideration for the international regulations [7] and the National standards GOST R ISO 10993-2-

Belgorod State National Research University, Belgorod, Russia. Address for correspondence: nadezhdin@bsu.edu.ru. S. V. Nadezhdin
2009 and GOST ISO 10993-6-2011. Specimens of titanium alloys with bioactive coatings were implanted under the skin of the experimental animals: BT6 alloy with large-porous coating (LPC) or BT1-0 pure titanium with microporous coating (MPC).

The implants were made using microarc oxidation technology at the Nanostructured Materials and Nanotechnologies Science, Education and Innovation Centre, Belgorod State National Research University $[1,2,6]$. The thickness of MPC was 11-12 $\mu$, roughness (Ra) 1.4-1.6 $\mu$ [6]. The thickness of LPC varied within 25-35 $\mu$, with Ra 5-6 $\mu$. More than 90\% of MPC surface was formed by pores $<5 \mu$. For LPC at least $50 \%$ surface were pores $>5 \mu$, some of them up to $25 \mu$. The surface roughness at the nanolevel (on the surface between pores of the $\mu$ size) was $80 \pm 30 \mathrm{~nm}$ for MPC and $100 \pm 30 \mathrm{~nm}$ for LPC. Microporous coating was presented by titanium and silicon oxides with calcium oxide level no more than $2 \mathrm{~mol} \%$, while the molar share of calcium oxide in LPC was $40 \mathrm{~mol} \%$ [6].

Ectopic osteogenesis was studied in vivo $[3,10]$. Eight Wistar rats received syngeneic red bone marrow. The animals were sacrificed by ether overdos- 
age, femoral bones were removed under sterile conditions, and red bone marrow cells were isolated. The resultant cell suspension was divided into 2 portions. One portion was applied onto implants and placed in Petri dishes. Experimental samples with implants were incubated in DMEM/F-12 (Gibco) supplemented with $10 \%$ fetal calf serum (HyClone), $100 \mathrm{nmol} / \mathrm{li}-$ ter dexamethasone phosphate (Shreya Life Sciences), $50 \mathrm{mg} /$ liter ascorbic acid (Sishui Xierkang Pharmaceutical Co.). Glycerophosphate $(10 \mathrm{mmol} / \mathrm{liter}$; Vector) was added to the culture medium instead of the implants in control samples. The other portion of the suspension was applied onto the implants which were then incubated for $45 \mathrm{~min}$ in DMEM/F-12 (Gibco) and implanted subcutaneously.

In experiments in vitro, formalin solution $(10 \%)$ was added to Petri dishes after 14 days and the cultures were stained with $10 \%$ Alizarin red (Sigma Aldrich). Calcium depositions indicating osteogenic differentiation of cells were detected under Eclipse E200 microscope (Nikon).

In vivo, the animals were sacrificed by ether overdosage after 60 days, and the implants with tissue fragments were removed. The tissue which grew on the implant was removed with a scalpel and plunged in $10 \%$ formalin. Histological preparations were processed routinely and stained with hematoxylin and eosin. Histological analysis was carried out under an Eclipse E200 microscope (Nikon). The area of new bone tissue was evaluated using NIS Elements D software (Nikon).

Scanning of the implant surface with evaluation of the morphology and integration of connective tissue elements were carried out using Quanta 200 3D scanning electron microscope (FEI Company). Bone tissue was differentiated from loose and compact con-

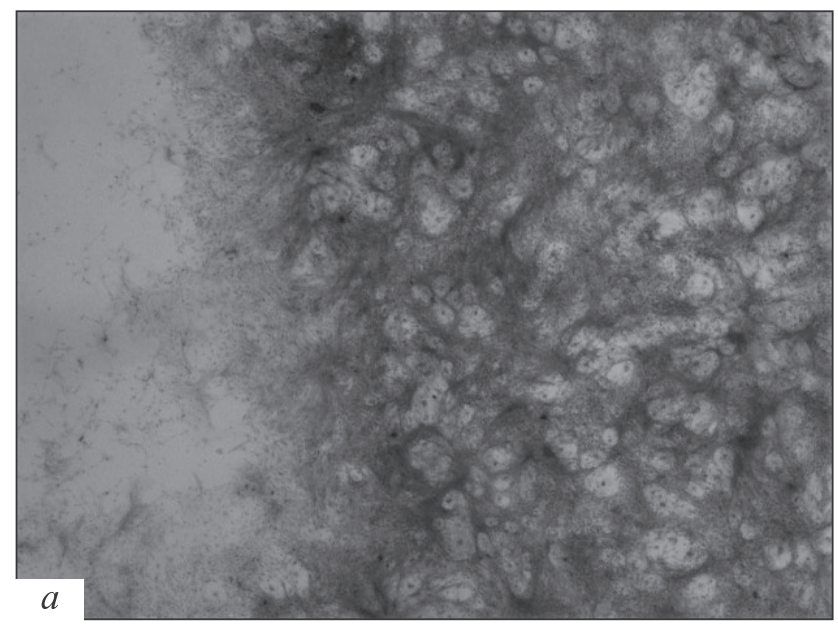

nective tissue by weight content (wt\%) of calcium and phosphorus using an attachment for X-ray spectral microanalysis (EDAX).

The results were statistically processed using Statistica 6.0 software.

\section{RESULTS}

Calcium-positive staining was found in experimental and control samples in vitro, no appreciable differences between them were detected (Fig. 1, a). In vivo, no signs of inflammatory reaction and tissue infection were detected 2 months after subcutaneous implantation of specimens with bioactive coating.

Macroscopic analysis of the implants showed connective tissue layers on the surface of all specimens. Bone tissue layers were clearly seen in the BT6-LPC group (Fig. 1,b), while in the BT1-0-MPC group, small fragments of bone tissue were surrounded by fibers of loose and compact connective tissue. Histological studies revealed the largest bone tissue area on BT6-LPC samples $\left(800 \pm 2 \mu^{2} v s .300 \pm 4 \mu^{2}\right.$ on the BT1-0-MPC implants).

Studies of implants in a scanning electron microscope confirmed the presence of fibrous connective tissue layers and bone tissue on the surfaces of specimens of both kinds (Fig. 2). Massive bone trabeculae alternating with compactly packed fibrillar structures forming a homogenous layer, were clearly seen on the surface of BT6-LPC implants. A different picture was seen on the surface of BT1-0-MPC implants: bone trabeculae were smaller and enveloped in fibrillar structures of various diameters with gaps between fragments.

Analysis of characteristic X-ray spectra showed the content of macroelements in fibrillar structures in

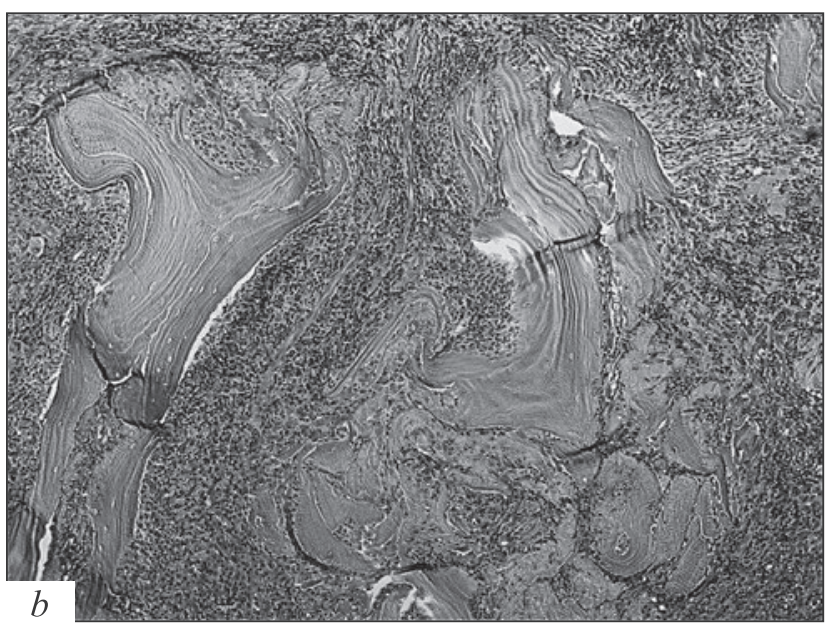

Fig. 1. Fragments of connective tissue formed in contact with BT6-LPC implant. a) Micropreparation, Ch30; in vitro - osteogenic cells, preosteoblasts round the implant; $b$ ) micropreparation, $\times 100$; in vivo - bone tissue surrounded by fibers of loose and compact connective tissue. 

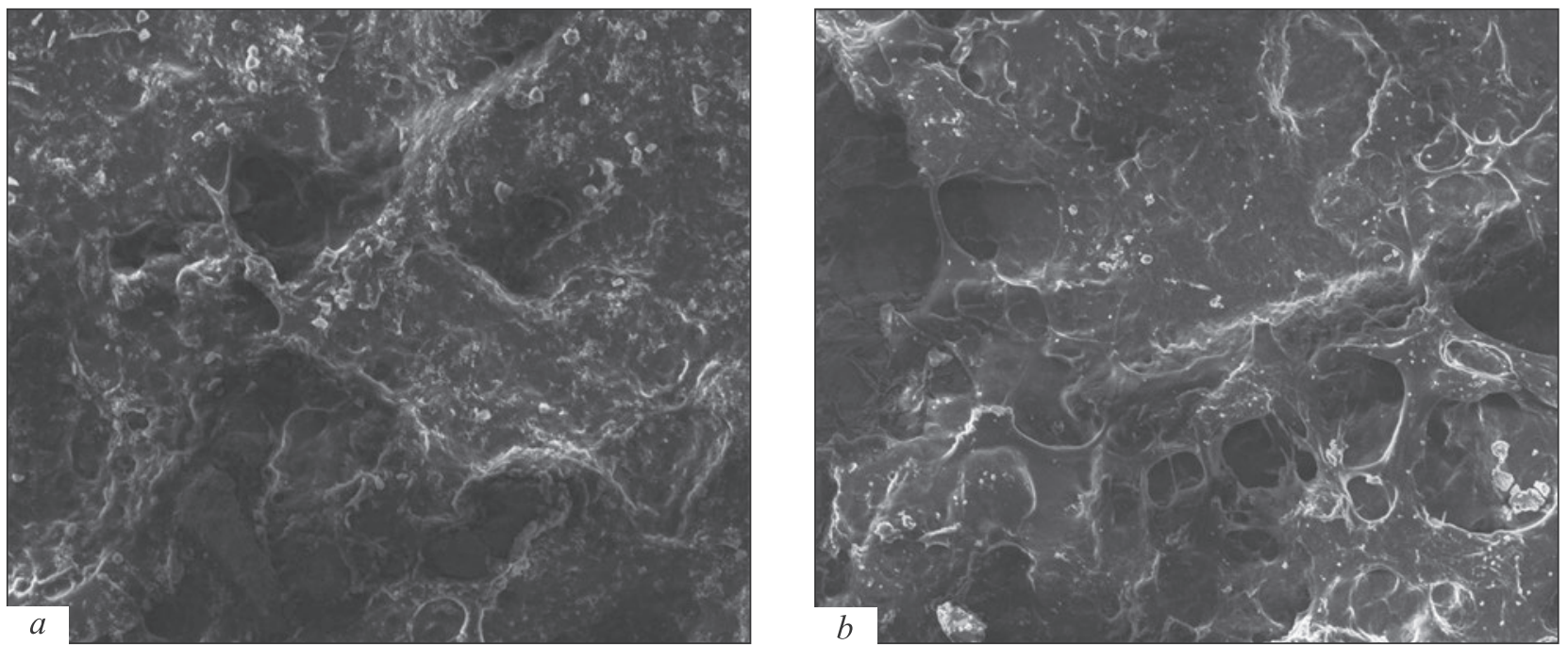

Fig. 2. Fragments of new bone tissue on the surface of BT6-LPC implant $(a, \times 6000)$ and BT1-0-MPC implant $(b, \times 4000)$ with abundant compact fibrous connective tissue.

all groups: calcium $-33 \pm 6 \mathrm{wt} \%$, phosphorus $67 \pm 6$ $\mathrm{wt} \%$. The content of calcium in new bone tissue trabeculae on BT6-LPC implants was $63 \pm 6 \mathrm{wt} \%$ and phosphorus $37 \pm 6 \mathrm{wt} \%$ vs. $60 \pm 6$ and $40 \pm 6 \mathrm{wt} \%$ for calcium and phosphorus, respectively, on BT1-0-MPC implants - hence, no appreciable differences between the groups were detected.

All implants used for subcutaneous inoculation are biocompatible. In vitro experiments showed that the presence of calcium-phosphorus layer on the implants promoted osteogenic differentiation of red bone marrow cells. The results of in vivo experiments indicate better osteogenic and osteoconductive characteristics of BT6-LPC implants. Well-developed surface relief of the implants with pores of various sizes forming channels in the inner layers, promotes rapid penetration of osteogenic cells, fibers, and bioactive substances essential for regeneration processes, into the depth of the implant. Homogenous surface relief of BT1-0-MPC does not stimulate the osteogenic and osteoconductive characteristics of these implants. Roughness of the surface at the nanolevel seems to be inessential in vivo; presumably, this parameter works at the earlier stages of bone tissue formation.

Hence, a space with 3D organization of the structure and sufficient levels of calcium phosphates in the coating of the material are obligatory conditions for the formation and integration of bone tissue with the implant.

The study was carried out on the equipment of Centre of Common Use "Diagnosis of Nanomaterials Structure and Characteristics", Belgorod State National Research University.

\section{REFERENCES}

1. Erubaev EA, Kolobov YR, Kuzmenko IN, Khramov GV, Ivanov MB, Manokhin SS. The influence of micro-arc oxidation on the fatigue titanium alloy VT6. Fundament. Issled. 2014;(12):2575-2579. Russian.

2. Kolobov YR. Nanotechnologies for the formation of medical implants based on titanium alloys with bioactive coatings. Nanotechnol. Rus. 2009;4(11-12):758-775.

3. Khlusov IA, Karlov AV, Pozhen'ko NS, Sukhodolo IV, Khlusova MY. Relationship between osteogenic characteristics of bone marrow cells and calcium phosphate surface relief and solubility. Bull. Exp. Biol. Med. 2006;141(1):99-103.

4. Cyster LA, Grant DM, Howdle SM, Rose FR, Irvine DJ, Freeman D, Scotchford CA, Shakesheff KM. The influence of dispersant concentration on the pore morphology of hydroxyapatite ceramics for bone tissue engineering. Biomaterials. 2005;26(7):697-702.

5. Dalby MJ, Gadegaard N, Tare R, Andar A, Riehle MO, Herzyk P, Wilkinson CD, Oreffo RO. The control of human mesenchymal cell differentiation using nanoscale symmetry and disorder. Nat. Mater. 2007;6(12):997-1003.

6. Gazizova MYu, Ivanov MB, Vershinina T.N. Investigation of corrosion behavior of bioactive coverings on commercially pure titanium and its alloys. J. Nano-Electron. Phys. 2015;7(4):04081(3).

7. Guide for the Care and Use of Laboratory Animals. Washington, 2011.

8. Karageorgiou V, Kaplan D. Porosity of 3D biomaterial scaffolds and osteogenesis. Biomaterials. 2005;26(27):5474-5491.

9. Li J, Dou Y, Yang J, Yin Y, Zhang H, Yao F, Wang H, Yao K. Surface characterization and biocompatibility of micro- and nano-hydroxyapatite/chitosan-gelatin network films. Mater. Sci. Eng: C. 2009;29(4):1207-1215.

10. Scott MA, Levi B, Askarinam A, Nguyen A, Rackohn T, Ting $\mathrm{K}$, Soo C, James AW. Brief review of models of ectopic bone formation. Stem Cells Dev. 2012;21(5):655-667. 